\title{
A new genus and new species of Telephanini (Coleoptera: Silvanidae) from Gabon
}

\author{
Michael KARNER ${ }^{1, *}$, Gianfranco SALVATO ${ }^{2} \&$ Marco ULIANA $^{3}$ \\ ${ }^{1}$ Section Entomology I, Forschungsinstitut Senckenberg, Senckenberganlage 25, \\ D-60325 Frankfurt am Main, Germany. \\ *Corresponding author: michael.karner@senckenberg.de \\ ${ }^{2,3}$ Museo di Storia Naturale, Santa Croce 1730, 30135 Venezia, Italy. \\ ${ }^{1}$ urn:1sid:zoobank.org:author:48E64F07-CDD3-4B4B-9C9A-24CBFCBBCB3D \\ ${ }^{2}$ urn:1sid:zoobank.org:author:50EBE48B-63DA-427A-B3F4-0C852E7DF7A8 \\ ${ }^{3}$ urn:Isid:zoobank.org:author:D5BE9B7E-F44F-4CE8-9BFA-1F498B0382D7
}

\begin{abstract}
A new genus and new species of Telephanini LeConte, 1861 are described based on specimens recently collected by an Italian expedition to Gabon. Bolianus giannae gen. et sp. nov. is characterized in particular by the presence of a longitudinal median groove along the head.
\end{abstract}

Key words. Africa, Silvanidae, Bolianus giannae, taxonomy

Karner M., Salvato G. \& Uliana M. 2015. A new genus and new species of Telephanini (Coleoptera: Silvanidae) from Gabon. European Journal of Taxonomy 130: 1-10. http://dx.doi.org/10.5852/ejt.2015.130

\section{Introduction}

In their diagnosis of Telephanini (Coleoptera, Silvanidae), Thomas \& Nearns (2008) list nine genera within the tribe. Aplatamus Grouvelle, 1912, Euplatamus Sharp, 1899 and Australophanus Thomas \& Nearns, 2008 are restricted to the New World, Indophanus Pal, 1981 was only found in India, and species of Megapsammoecus Karner, 1995 were recorded from India and China, respectively. For Africa, Madagascar and the Reunion Islands, members of three genera were recorded: Psammoecus Latreille, 1829, Telephanus Erichson, 1846 (Madagascar, Reunion) and Psammaechidius Fairmaire, 1882 (Madagascar). Cryptamorpha desjardinsi (Guérin-Méneville, 1844) is a cosmopolitan species (Thomas \& Nearns 2008); no other members, however, of Cryptamorpha Wollaston, 1854 have been recorded from Africa; therefore, we don't consider Cryptamorpha to be native to Africa.

A sample of beetles recently collected in Gabon by Silvano Biondi and Maurizio Pavesi contained a remarkable new species of Telephanini, representing a new genus that is described here.

\section{Material and Methods}

The specimens were collected during expeditions to the National Park of Ivindo, Gabon, organized by the Museo di Storia Naturale del Salento, Calimera, Italy in collaboration with CENAREST (Centre National de la Recherche Scientifique et Technologique, Gabon). The park is located in the northeastern 
part of Gabon at an altitude of about $500 \mathrm{~m}$. The material was collected at light, close to the Ipassa Research Station, in a somewhat degraded forest location (but surrounded by well-preserved primary forest) in the northern part of the park. Durante (2012) provides more detailed information on the locality and ecological circumstances.

For dissection of genitalia, the method described by Karner (2012) was used. One male paratype was dissected for examination of mouthparts and coxal cavities. For photography, the dissected body parts were temporarily embedded in glycerol gelatin to enable precise orientation. After study, structures were embedded in dimethylhydantoin formaldehyde resin (Steedman 1958) on cellulose acetate labels and attached to the pins of the respective specimens.

Observations and measurements were made with an Olympus SZX16 stereo microscope. Macro photographs were taken with a Canon EOS 650D digital camera and an MP-E $65 \mathrm{~mm}$ macro objective. Higher magnifications were obtained with Mitutoyo M Plan 10× and 20× apochromatic microscope objectives mounted on Asahi Takumar $200 \mathrm{~mm}$ and Carl Zeiss MC Sonnar $135 \mathrm{~mm}$ telephoto lenses in varying combinations. Photographs of genitalia were taken with a Canon EOS 650D digital camera attached to an Olympus $\mathrm{CH}$ microscope. Images and image layers were processed with Zerene Stacker (Version 1.04 Build T201311272225), Adobe Lightroom 5.7 and GIMP (Version 2.8.0) software.

\section{Results}

\section{Taxonomy}

Class Hexapoda Blainville, 1816

Order Coleoptera Linnaeus, 1758

Family Silvanidae Kirby, 1837

Subfamily Brontinae Erichson, 1845

Tribe Telephanini LeConte, 1861

Bolianus gen. nov. urn:Isid:zoobank.org:act:2D779708-0649-41F3-A501-0594D14F7775

\section{Type species}

Bolianus giannae sp. nov.

\section{Differential diagnosis}

Within the Telephanini, Bolianus gen. nov. is closely related to Psammaechidius Fairmaire, 1882, but differs by the distinct median frontal groove, large eyes, short and moderately curved temples, maximum width of pronotum near middle, and the tuberculate lateral margins of the pronotum.

\section{Etymology}

The peculiar median groove along the head prompted us to derive the generic name from the 'Bolians', a fictitious species from the universe of the science fiction series 'Star Trek', characterized by a vertical suture running along the midline of head and face.

\section{Description}

The genus shares the characteristics of Brontinae: Telephanini as described by Thomas \& Nearns (2008), plus: apical maxillary palpomere securiform (Fig. 7); apical labial palpomere large, rounded (Fig. 8); antennal scape elongate; frons with two lateral lines and one median line; eyes large; temples evenly curved, narrowed immediately behind eyes; maximum pronotal width near middle; lateral margins 
of pronotum tuberculate; anterior coxal cavities closed (Fig. 9); anterior and middle coxae separated narrowly (Fig. 10); scutellum with transverse carina; elytra with 10 rows of punctures; scutellary striole present; $2^{\text {nd }}$ and $3^{\text {rd }}$ tarsomeres with single ventral lobe (Fig. 11); abdominal ventrites simple (Fig. 12); aedeagus inverted, parameres well developed.

Bolianus giannae sp. nov. urn:Isid:zoobank.org:act:668CE306-2286-429C-A65F-17CEE811417E

Figs 1-14

\section{Diagnosis}

As for genus.

\section{Etymology}

The species is dedicated by Gianfranco Salvato to his wife, Gianna Polo.

\section{Material examined}

\section{Holotype}

GABON: O’, Ipassa-Makokou, 0³0’43” N, 1248’13” E, 500 m, 25 Nov. 2013, leg. M. Pavesi (Museo di Storia Naturale di Venezia, Venice, Italy).

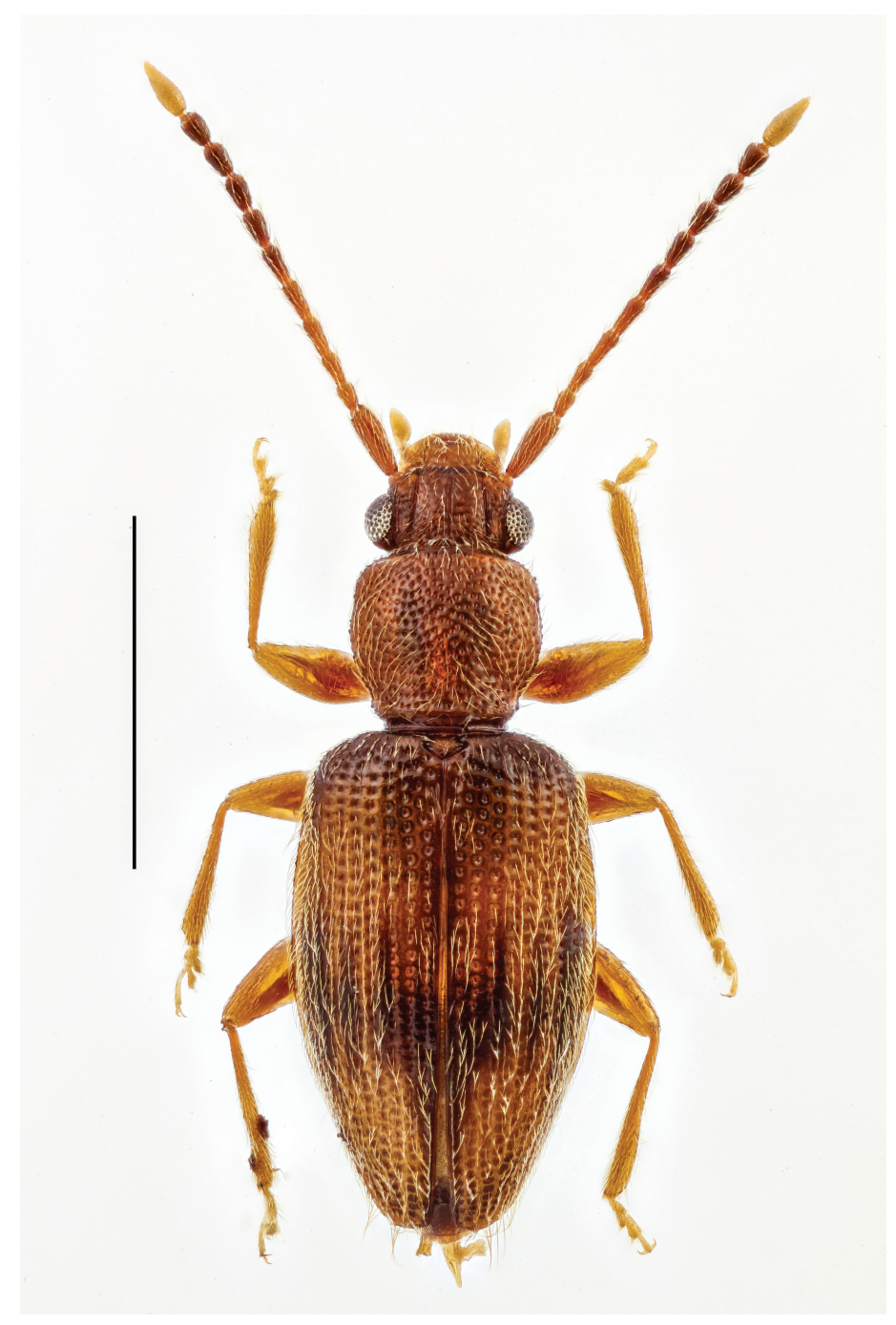

Fig. 1. Bolianus giannae gen. et sp. nov., holotype, habitus. Scale bar $=2.0 \mathrm{~mm}$. 


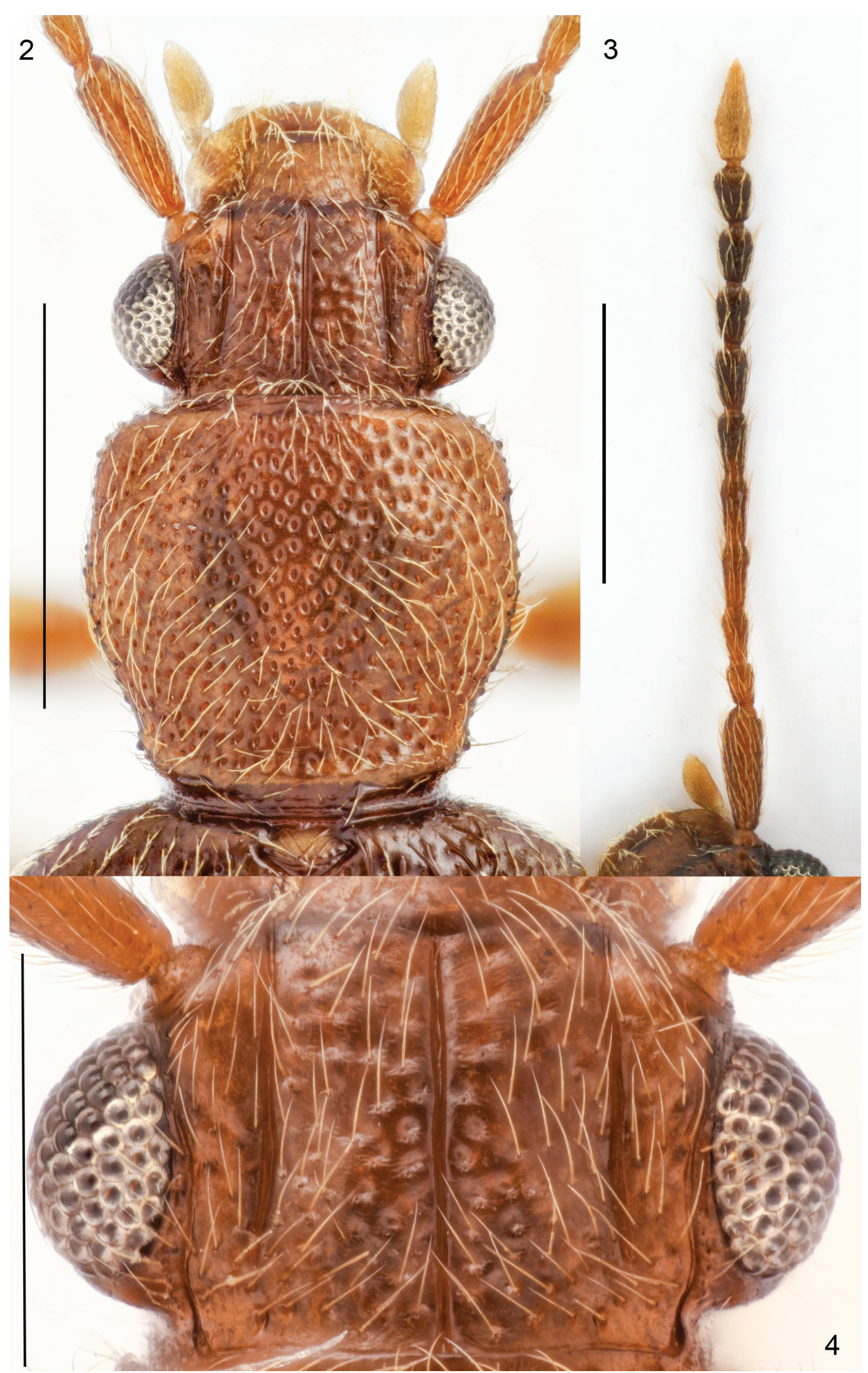

Figs 2-4. Bolianus giannae gen. et sp. nov., holotype. 2. Head and pronotum. 3. Right antenna. 4. Detail of head. Scale bars: $2-3=1.0 \mathrm{~mm}, 4=0.5 \mathrm{~mm}$. 
Paratypes $(3 \hat{\jmath} \hat{\partial}, 3$ 우 $)$

GABON: $3 \widehat{\partial}, 2$ $\uparrow$, same data as holotype ( $1 \hat{\jmath}$ [dissected] and $1 q$ in coll. Museo di Storia Naturale di Milano, Milan, Italy; $1 \hat{\delta}$ in coll. Museo di Storia Naturale del Salento, Calimera, Italy; 1 q in coll. Gianfranco Salvato; 1 t in coll. Michael Karner, later in coll. Forschungsinstitut Senckenberg, Frankfurt, Germany); 1 ㅇ, same locality as holotype, 16 Feb.-1 Mar. 2012, leg S. Biondi (in coll. Silvano Biondi, Vicenza, Italy).

\section{Description of holotype}

Body (Fig. 1). Castaneous, elongate oval, total length from apical margin of clypeus to apex of elytra $4.55 \mathrm{~mm}$. Elytra darkened near base, with dark transverse maculae near middle. Antennae light castaneous, apical $2 / 3$ of $6^{\text {th }}$ antennomere darkened, $7^{\text {th }}-10^{\text {th }}$ antennomeres blackish brown, $11^{\text {th }}$ antennomere yellowish brown. Legs brown.

HEAD (Figs 2-3). Eyes prominent, rounded, eye length from anterior to posterior margin $0.30 \mathrm{~mm}$, eye distance across vertex $0.64 \mathrm{~mm}$. Temples well defined and moderately curved, angle between temple and longitudinal axis of head $64^{\circ}$; head width across eyes $0.97 \mathrm{~mm}$, length from apical margin of clypeus to imaginary line between hind margins of eyes $0.68 \mathrm{~mm}$. Punctures on vertex 0.5 times as large as an eye facet diameter, spaces between punctures irregular, between 0.5 and about 1.5 times their diameter, somewhat irregular. Pubescence composed of semierect setae about 0.25 times as long as eye length, directed anteriorly. Microsculpture shallow, reticulate. Lateral frontal lines deep, straight, slightly converging anteriorly, almost attaining posterior margins of eyes. Central frontal line deep, anterior end not attaining frontoclypeal suture, posterior end attaining basal ridge of head. Additional impressions running close to dorsal margins of eyes from anterior fifth of eyes to basis of head. Antennae long, slender, attaining almost middle of elytra, length $2.75 \mathrm{~mm}$; antennomere proportions, starting from scape, as follows: $3.1: 1.0: 1.3: 1.6: 1.7: 1.6: 1.5: 1.4: 1.4: 1.4: 2.6$ (Fig. 3 ).

Pronotum (Fig. 2). Widest near middle, about 1.1 times as wide as head; moderately wider than long; maximum width $1.10 \mathrm{~mm}$, length $1.00 \mathrm{~mm}$. Area near posterior margin slightly depressed. Lateral margins with minute tubercles, which are slightly larger near anterior and posterior angles. Anterior part of lateral margin almost straight, slightly diverging towards middle, slightly sinuate from middle to base. Punctures on pronotal disk larger than on vertex, slightly smaller than an eye facet, somewhat irregular with distances between punctures ranging from 0.5 times to 2 times their diameter. Pubescence composed of semierect setae about 0.3 times as long as eye length, directed anteromedial. Microsculpture shallow, reticulate.

Legs. Simple, slender; $2^{\text {nd }}$ and $3^{\text {rd }}$ tarsomeres lobed and with dense pubescence on soles.

ELYTRA. Oval, 1.68 times as long as pronotum, widest just in front of middle, length along suture including scutellum $2.84 \mathrm{~mm}$, combined maximum width $1.68 \mathrm{~mm}$. Rows of punctures on elytral disk about $2 / 3$ as wide as interstices; pubescence composed of long, semierect setae; strial setae as long as interstrial setae; interstrial setae predominantly in single rows, in several, irregularly distributed places also in double rows; $10^{\text {th }}$ stria with 7 distinctly enlarged, deep punctures. Microsculpture absent.

AвDOMEN. Abdominal ventrites simple.

Aedeagus (Figs 13-14). Parameres of holotype wide, parallel-sided, almost three times as long as wide; median lobe slender, lancet-shaped. Fig. 14C shows the parameres of a male paratype that were temporarily flattened under a cover slip to exhibit their shape in perpendicular view. 


\section{Variation}

The paratypes vary in body length from 4.65 to $5.10 \mathrm{~mm}$. Elytra of females slightly more rounded than those of males, widest behind middle.

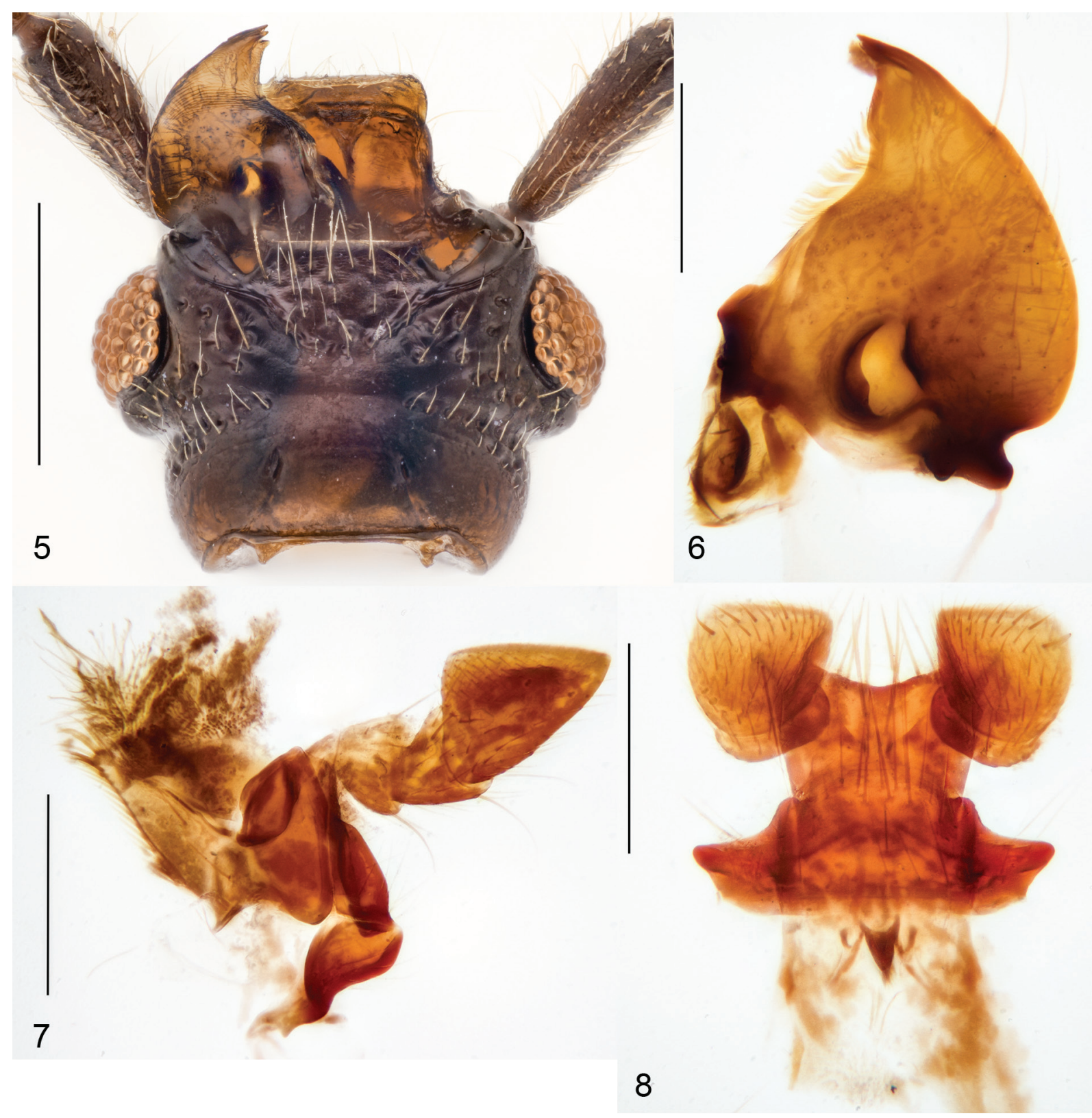

Figs 5-8. Bolianus giannae gen. et sp. nov., paratype. 5. Ventral view of head (left mandible, maxillae and labium removed). 6. Left mandible, ventral view. 7. Left maxilla, ventral view. 8. Labium, ventral view. Scale bars: $5=0.5 \mathrm{~mm}, 6-8=0.2 \mathrm{~mm}$. 


\section{Discussion}

The new genus is very closely related to Psammaechidius Fairmaire, 1869, but can easily be distinguished from all other genera of Telephanini by the presence of three frontal lines. It differs from Psammaechidius (Fig. 15) also by the character states given in the differential diagnosis.

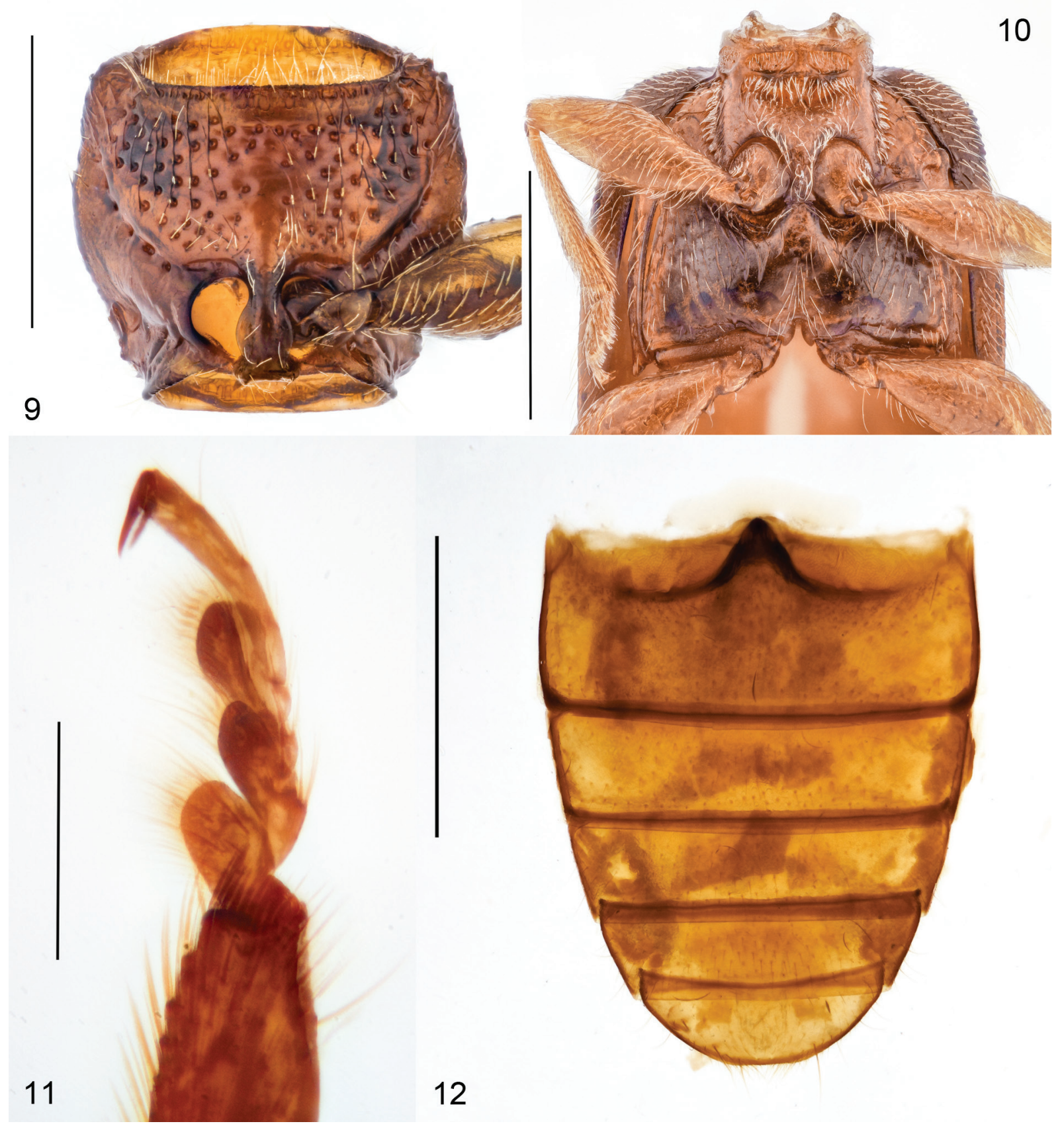

Figs 9-12. Bolianus giannae gen. et sp. nov., paratype. 9. Pronotum, ventral view (right anterior leg removed). 10. Meso- and metathorax, ventral view. 11. Right anterior tarsus. 12. Abdominal ventrites. Scale bars: $9-10,12=1.0 \mathrm{~mm}, 11=0.2 \mathrm{~mm}$. 
Thomas \& Nearns (2008) provide a key to the genera of Telephanini. Bolianus could easily be placed in that key by inserting a couplet ' 0 ' before couplet 1 as follows:

0 Frons with median groove Bolianus

- Frons without median groove ..1

Since the remaining key given by Thomas \& Nearns (2008) remains unchanged, it is not reproduced here to avoid redundancy.
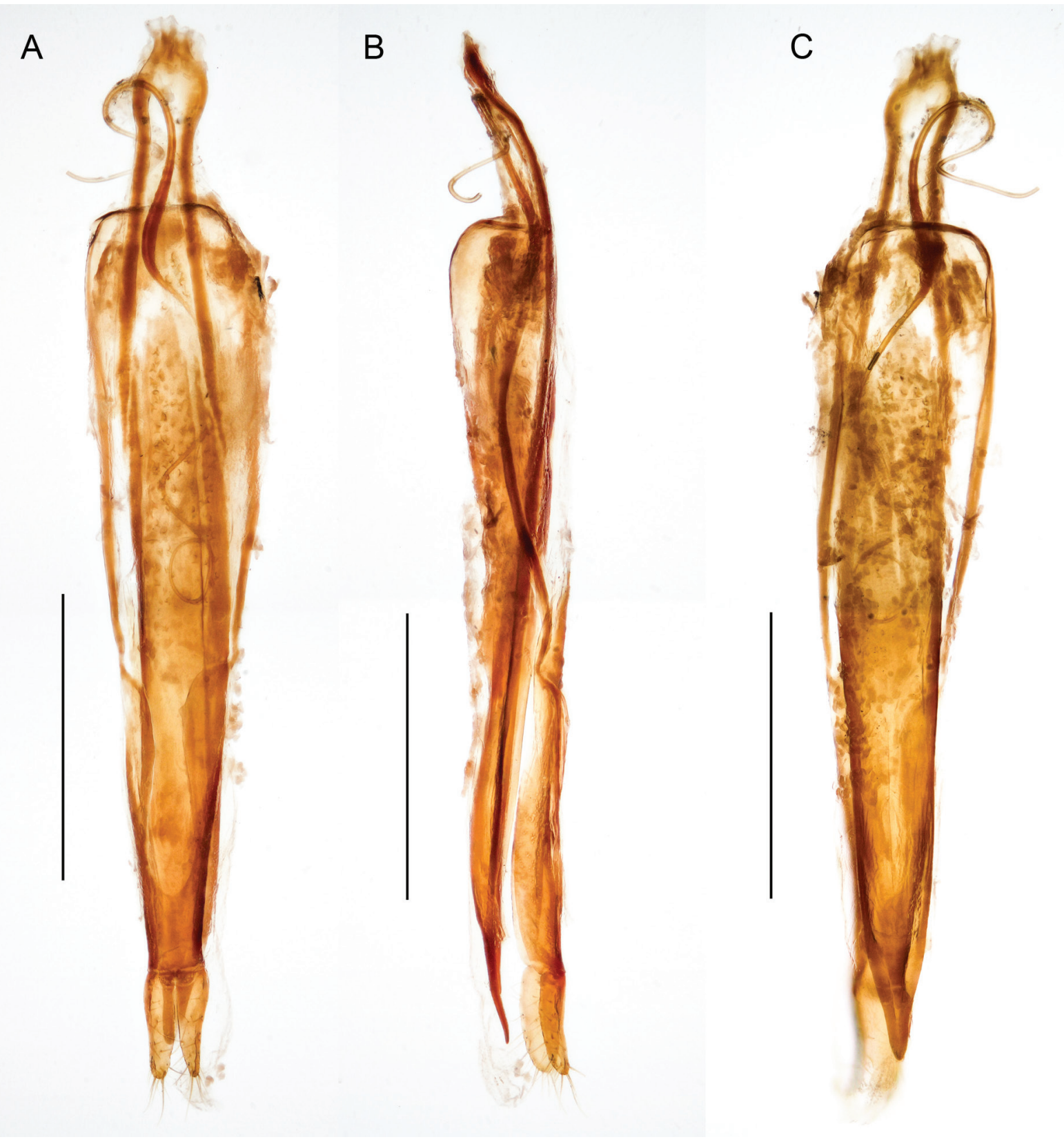

Fig. 13. Bolianus giannae gen. et sp. nov., holotype, aedeagus. A. Ventral view. B. Lateral view. C. Dorsal view. Scale bars $=0.5 \mathrm{~mm}$. 


\section{A}

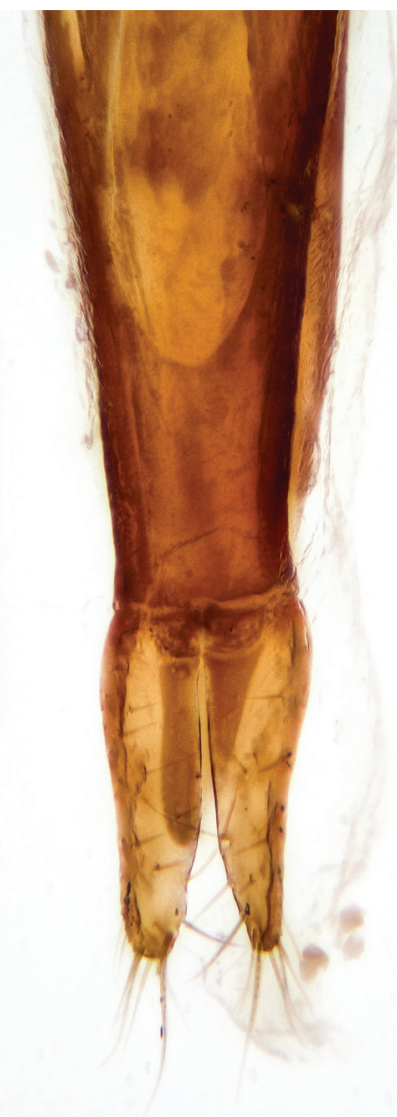

B

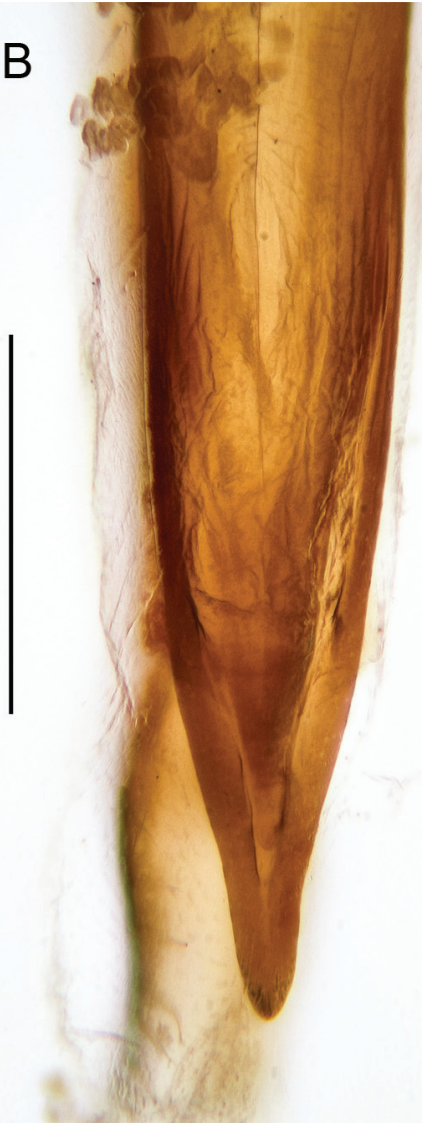

C

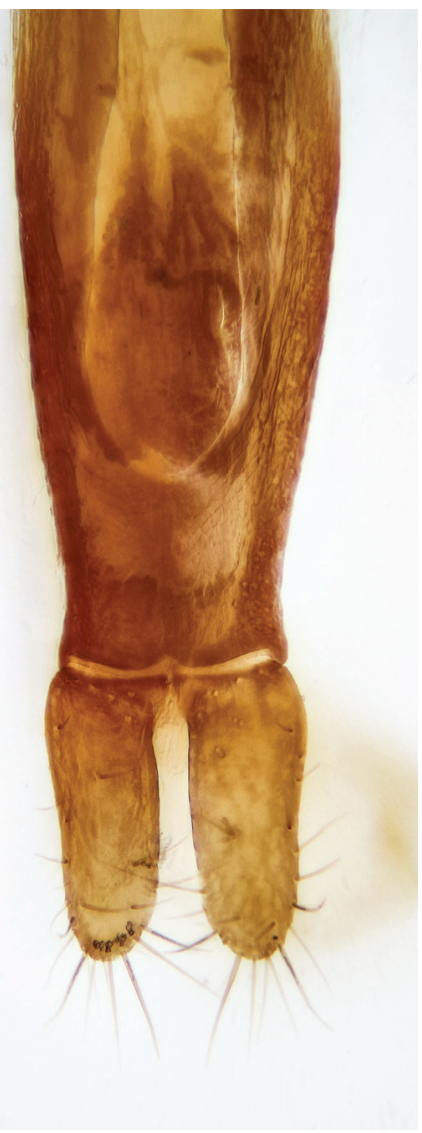

Fig. 14. Bolianus giannae gen. et sp. nov. A-B. Holotype, detail of aedeagus. A. Parameres, ventral view. B. Median lobe, dorsal view. - C. Paratype, parameres, ventral view. Scale bars $=0.2 \mathrm{~mm}$.

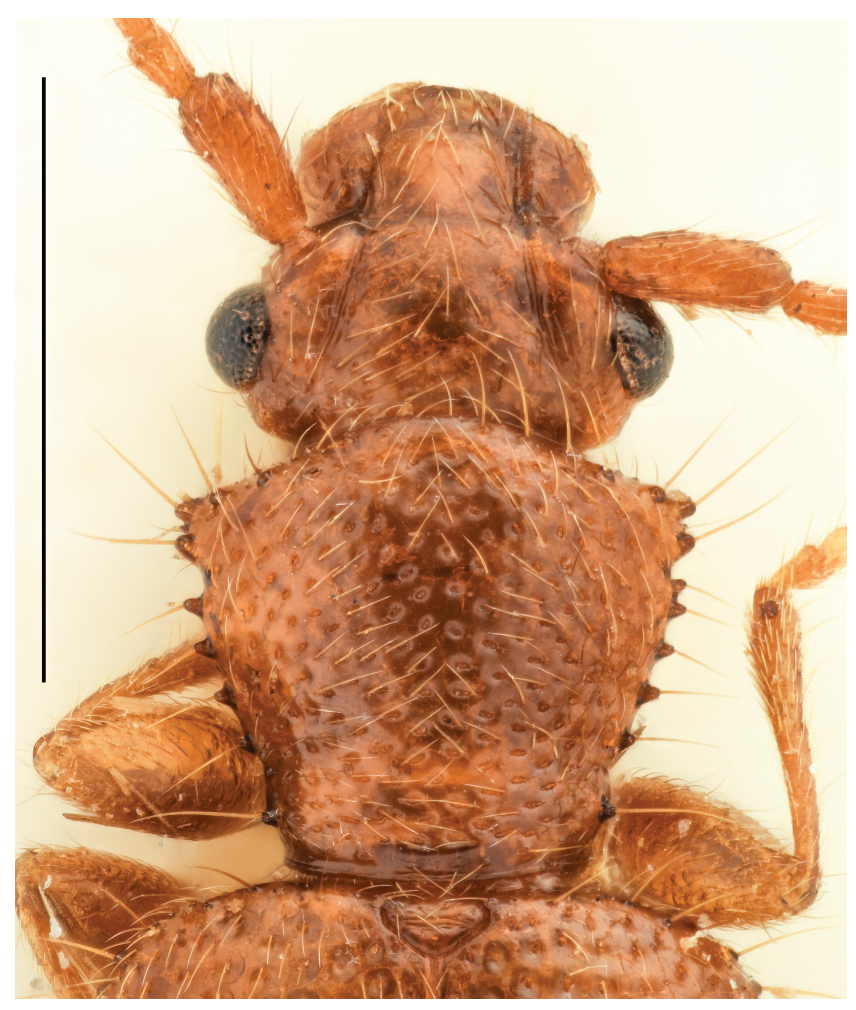

Fig. 15. Psammaechidius spinicollis Fairmaire, 1862, specimen from Fampanambo, Madagascar, Sep. 1959, leg. Vadon (coll. Michael Karner), head and pronotum. Scale bar $=1.0 \mathrm{~mm}$. 


\section{Acknowledgements}

Our gratitude goes to Maurizio Pavesi, who collected the largest part of the type series and proposed the study of this species to Gianfranco Salvato, and to Silvano Biondi, who entrusted an additional specimen to us. We also wish to thank Antonio Durante (Museo di Storia Naturale del Salento) for providing information on the area where the material was collected. Furthermore, we thank Michael C. Thomas (Gainesville, Florida) for constructively criticizing our manuscript.

\section{References}

Durante A. 2012. The genus Afrasura Durante, 2009 in Gabon, with description of five new species and a new species group (Erebidae: Arctiinae: Lithosiini). Zootaxa 3478: 383-398.

Karner M. 2012. A revision of African Psammoecus (Coleoptera, Silvanidae) and descriptions of two new species from the collection of the Musée royal de l'Afrique centrale. European Journal of Taxonomy 17: 1-31. http://dx.doi.org/10.5852/ejt.2012.17

Steedman H.F. 1958. Dimethyl hydantoin formaldehyde: Anew water-soluble resin for use as a Mounting medium. Quarterly Journal of Microscopical Science 99: 451-452.

Thomas M.C. \& Nearns E.H. 2008. A new genus of telephanine Silvanidae (Coleoptera: Cucujoidea), with a diagnosis of the tribe and key to genera. Insecta Mundi 0048: 1-14. Available from http:// digitalcommons.unl.edu/insectamundi/576 [accessed on 30 Mar. 2015]

Manuscript received: 30 March 2015

Manuscript accepted: 9 June 2015

Published on: 23 July 2015

Topic editor: Koen Martens

Desk editor: Kristiaan Hoedemakers

Printed versions of all papers are also deposited in the libraries of the institutes that are members of the EJT consortium: Muséum National d'Histoire Naturelle, Paris, France; Botanic Garden Meise, Belgium; Royal Museum for Central Africa, Tervuren, Belgium; Natural History Museum, London, United Kingdom; Royal Belgian Institute of Natural Sciences, Brussels, Belgium; Natural History Museum of Denmark, Copenhagen, Denmark. 